\title{
Implementation of Autonomous Maintenance in Total Productive Maintenance
}

\section{Implementasi Autonomous Maintenance Dalam Penerapan Total Productive Maintenance}

\author{
Juli Guritno, Atikha Sidhi Cahyana \\ \{juliguritno10@gmail.com, atikhasidhi@umsida.ac.id\}
}

Program Studi Teknik Industri, Fakultas Sains dan Teknologi, Universitas Muhammadiyah Sidoarjo

\begin{abstract}
The purpose of this research is to increase the availability rate, Performance rate, and OEE value on pipe extruder line 9 at PT. Wahana Tunas Utama Rucika is engaged in manufacturing PVC pipe products (Poly Vinyl Chloride). In order to increase productivity, Total Productive Maintenance (TPM) is measured by calculating OEE. The method used in solving this problem is the 8 pillars of TPM with the Autonomous Maintenance (AM) method. The implementation of the TPM pillar aims to increase the knowledge, responsibility, and skills of production operators related to machines so that overall productivity will increase. AM uses a structured and documented system so that this program can run consistently. The results of the implementation of the proposed improvements showed that the Availability rate had to increase by $3.61 \%$, the Performance rate had to increase by $3.41 \%$ and OEE had to increase by $3.25 \%$ after the proposed improvements 6 months.
\end{abstract}

Keywords - Autonomous Maintenance; PVC pipe (PolyVinyl Chloride); Total Productive Maintenance

Abstrak. Tujuan dari penelitian ini adalah meningkatkan nilai availability rate, performance rate dan Overall Equipment Effectiveness (OEE) pada pipe extruder line 9 di PT Wahana Tunas Utama Rucika yang bergerak dalam bidang manufaktur penghasil produk pipa PVC (PolyVinyl Chloride). Untuk dapat meningkatkan produktivitas maka dilakukan pengukuran Total Productive Maintenance (TPM) dengan perhitungan OEE. Adapun metode yang digunakan dalam penyelesaian permasalahan menggunakan 8 pilar TPM dengan metode Autonomous Maintenance (AM) Implementasi pilar TPM bertujuan untuk meningkatkan pengetahuan, tanggung jawab dan keterampilan operator produksi terkait mesin, sehingga akan meningkat produktivitas secara keseluruhan. AM menggunakan sistem yang terstruktur dan terdokumentasi sehingga program ini dapat berjalan dengan konsisten. Hasil dari implementasi usulan perbaikan didapatkan nilai Availability rate meningkat sebesar 3,61\%, Performance rate meningkat sebesar 3,41\% dan OEE meningkat sebesar 3,25\% setelah dilakukan usulan perbaikan selama 6 bulan.

Kata Kunci - Autonomous Maintenance; Pipa PVC (PolyVinyl Chloride); Total Productive Maintenance

\section{Pendahuluan}

Dalam dunia perindustrian dukungan teknologi sangatlah penting bahwa dengan adanya dukungan teknologi sangat mempengaruhi kegiatan produksi, selain itu dukungan teknologi juga sangat mempengaruhi jumlah produk dan kualitas. Apabila kita menginginkan kegiatan produksi dan jumlah produk kualitas yang baik maka kita dapat membuktikan dengan pengukuran produktivitas pada mesin dan fasilitas produksi. Dengan adanya perawatan mesin yang baik dapat menjamin sistem kerja sebuah mesin dapat berjalan dengan baik, efektif, efisien, optimal, fungsional dan ekonomi semua ini dilakukan demi menjamin dan menunjang kegiatan perawatan mesin [4]. Sebuah analisa sangatlah dibutuhkan untuk membuat kegiatan manajemen perawatan menjadi lebih baik. Yang mana nantinya dapat digunakan sebagai dasar perlakuan terhadap gejala-gejala dari kerusakan, serta diharapkan mampu mengantisipasi gejala-gejala dan menjamin kualitas produk, serta kemampuan ketersediaan mesin tersebut.

Hal ini sejalan dengan penelitian yang akan diambil di PT Wahana Tunas Utama Rucika, yang mana perusahaan tersebut bergerak dalam bidang manufaktur penghasil produk pipa PVC (Poly Vinyl Chloride). PT Wahana Tunas Utama Rucika ini memproduksi jenis pipa AW dan pipa D, Pipa jenis AW merupakan jenis pipa yang bertekanan dan pipa jenis D merupakan pipa yang tidak bertekanan. Dalam memproduksi pipa PVC PT. Wahana Tunas Utama Rucika masih kurang dalam pencapaian produktivitas.

Dari 3 line extruder pipe data yang diambil persentase OEE selama 3 bulan Pipe Extruder Line 9 93,90\%, Pipe Extruder Line 10 94.45\%, Pipe Extruder Line 11 95.10\%. Penelitian ini terdapat pada Pipe extruder Line 9 karena persentase OEE rendah selama 3 bulan didapat data availability rate 93,40\%, performance rate $92,10 \%$ dan quality rate $96,20 \%$.

Dengan adanya permasalahan mengenai pencapaian availability rate, performance rate dan nilai Overall Equipment Effectiveness (OEE) pada pipe extruder line 9 yang masih rendah, peneliti memilih menggunakan metode Autonomous Maintenance (AM) untuk meningkatkan produktivitas pipe extruder line 9. 


\section{MeTODE}

Autonomous Maintenance (AM) adalah konsep perawatan mesin yang melibatkan operator produksi sebagai pengguna untuk melakukan perawatan dasar. Implementasi pilar ini bertujuan untuk meningkatkan pengetahuan, ketrampilan, dan tanggung jawab operator produksi terkait mesin, sehingga produktivitas akan meningkat secara keseluruhan. Autonomous Maintenance menggunakan sistem yang terstruktur dan terdokumentasi sehingga program ini dapat berjalan dengan konsisten. Pengembangan Autonomous Maintenance (AM) untuk identifikasi penyebab masalah kerusakan peralatan dan cacat kualitas bahwa kerugian dihasilkan dari pola dan perilaku pemikiran manusia tanpa perubahan dramatis dalam cara berpikir Zero Breakdowns dan Zero Defects tidak akan pernah bisa dicapai. Sikap yang paling dibutuhkan oleh perusahaan saat ini adalah pendekatan inovatif yang menghasilkan langkahlangkah penanggulangan [12].

Dengan langkah-langkah yang diperlukan untuk melakukan tugas menghilangkan, mengurangi, atau menyederhanakan dan peningkatan kinerja secara keseluruhan [11].

Untuk memperoleh data primer dan sekunder perlu dilakukan pengambilan data secara langsung pada objek penelitian, berikut adalah :

1. Data Primer

a. Observasi, pengumpulan data mesin yang digunakan dalam proses produksi dilakukan dengan melihat dan mengadakan pengamatan langsung terhadap Extruder line 9 beserta downstream lainnya.

b. Wawancara, mengadakan tanya jawab kepada Operator, Formen, Supervisor, dan Maintenance karena selalu bekerja di sekitar peralatan sepanjang waktu dengan permasalahan yang sering terjadi pada mesin.

2. Data Sekunder

Studi pustaka, mengambil bahan dari literasi untuk mendapatkan informasi yang mendukung tentang permasalahan pada mesin extruder line 9.

Pada tahapan ini akan dilakukan pengolahan data menggunakan pilar TPM dengan metode Autonomous Maintenance (AM) disesuaikan dengan permasalahan yang ada di lapangan adapun metode ini hanya sampai pada AM tahap 3 dari 7 tahap yang ada pada Autonomous Maintenance (AM) dengan sistematis sebagai berikut :

Tahap 1 Pembersih awal atau Total clean out (TCO). Tujuan langkah ini adalah untuk membersihkan peralatan atau mesin di dalam dan di luar secara menyeluruh membuat tagging, foto before-after dan mendaftar area sumber kotor, sumber bocor, area yang sulit di cleaning, inspection, lubrication dan tightening (CILT) serta membuat standar cleaning, checklist cleaning dan training.

Tahap 2 Mereduce waktu cleaning : Dengan menghilangkan dan eliminir sumber bocor, kotor dan area yang sulit di cleaning, inspeksi, lubrikasi dan tightening (CILT). Tujuan dari tahap ini adalah untuk mendeteksi dan menghapus atau mengurangi sumber pencemaran dan sulit dijangkau, yang membuatnya sulit untuk membersihkan mesin dan akses ke area kritis. Hasilnya akan mempersingkat waktu cleaning, inspeksi, lubrikasi dan tightening (CILT).

Tahap 3 Mengurangi waktu lubrikasi : Dengan menentukan titik lubrikasi, daftar poin lubrikasi, kode lubrikasi, standar lubrikasi, checklist lubrikasi dan training. Tujuan dari langkah ini adalah pengenalan standar lubrikasi, jenis lubrikasi serta waktu lubrikasi.

Berikut ini merupakan diagram alir penelitian untuk meningkatkan nilai Availability rate, Performance rate dan Overall Equipment Effectiveness (OEE) pada pipe extruder line 9. Gambaran umum dari keseluruhan sistem yang dirancang dapat terlihat pada alur penelitian yang ditunjukkan oleh Gambar 1.

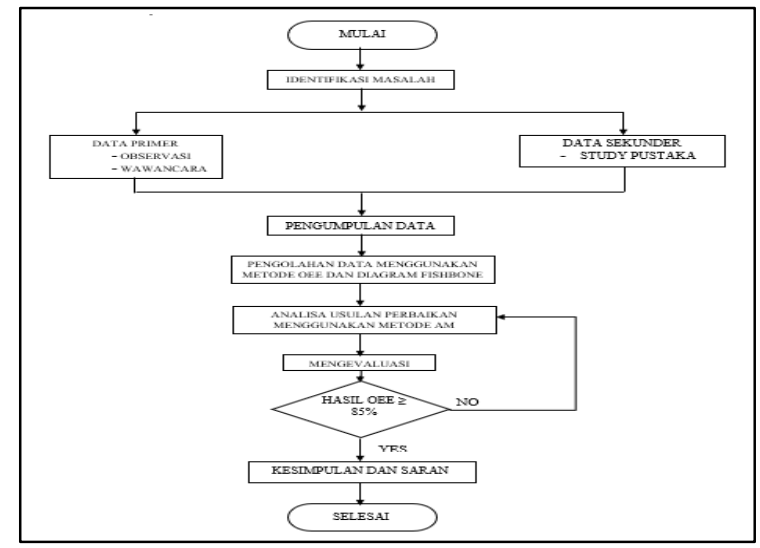

Gambar 1. Alur Penelitian

Berdasarkan alur penelitian pada gambar 1 telah dijelaskan bahwa tahapan-tahapan dimulai dari tahapan pengumpulan data, tahapan pengolahan data menggunakan metode OEE dan diagram fishbone, tahapan analisa usulan perbaikan menggunakan metode AM, tahapan mengevaluasi jika hasil OEE lebih kecil dari 85\% maka kembali ke 
tahapan analisa usulan perbaikan menggunakan metode AM dan jika hasil OEE lebih besar dari 85\% maka penelitian selesai.

\section{Hasil dan Pembahasan}

\section{A. Pengumpulan data}

Berdasarkan latar belakang perumusan masalah yang telah dikemukakan maka dilakukan pengumpulan data yang digunakan dalam implementasi Autonomous Maintenance di extruder line 9 data tersebut berupa evaluasi OEE Line 9 selama 6 bulan tahun 2019. Data yang diperlukan tersebut dijelaskan sebagai berikut :

Availability rate

Availability adalah mengukur efektivitas dari ketersediaan mesin untuk memproduksi item produk yang berdasarkan pada jadwal. Berdasarkan pada pengumpulan data berikut perhitungan metriknya:

$$
\text { Availability }=\frac{\text { opration time }}{\text { Loading time }} \times 100 \% \quad \ldots .1
$$

Untuk nilai availability selama 6 bulan tahun 2019 yaitu:

$$
=\frac{1682}{1898,5} \times 100 \%=88,60 \%
$$

Dengan cara ini didapat nilai availability pada extruder line 9 selama 6 bulan tahun 2019 seperti yang ditunjukkan pada Tabel 1 berikut:

Tabel 1. Availability Rate 2019

\begin{tabular}{ccc}
\hline Operation time (hours) & Loading time (hours) & AR \% \\
\hline 1682 & 1898,5 & $88,60 \%$ \\
\hline
\end{tabular}

Performance rate

Performance adalah perbandingan antara actual processing time (hours) dengan operation time (hours) yang digunakan untuk mengukur kemampuan mesin untuk menghasilkan item yang dinyatakan dalam persentase berikut perhitungan metriknya:

$$
\text { Performance }=\frac{\text { actual processing time }}{\text { operation time }} \times 100 \% \quad \ldots . .2
$$

Untuk nilai Performance selama 6 bulan tahun 2019 yaitu:

$$
=\frac{1523}{1682} x 100 \%=90,55 \%
$$

Dengan cara ini didapat nilai Performance pada extruder line 9 selama 6 bulan tahun 2019 seperti yang ditunjukkan pada Tabel 2 berikut:

Tabel 2. Performance Rate 2019

\begin{tabular}{ccc}
\hline Actual processing time (hours) & Operation time (hours) & PR \% \\
\hline 1523 & 1682 & $90,55 \%$ \\
\hline
\end{tabular}

Quality rate

Quality digunakan untuk menunjukkan waktu yang hilang saat proses produksi atau Hours processed amount (jumlah produk yang diproses / jam) dan Hours defect amount (jumlah produk yang cacat/ jam). Berdasarkan pada pengumpulan data berikut perhitungan metriknya:

$$
\text { Quality }=\frac{\text { hours processed amount }- \text { hours defect amount }}{\text { hours processed amount }} \times 100 \% \ldots . .3
$$

Untuk nilai Quality selama 6 bulan tahun 2019 yaitu:

$$
=\frac{1411-112}{1411} \times 100 \%=92,06 \%
$$

Dengan cara ini didapat nilai Quality pada extruder line 9 selama 6 bulan tahun 2019 seperti yang ditunjukkan pada Tabel 3 berikut:

Tabel 3. Quality Rate 2019

\begin{tabular}{cccc}
\hline $\begin{array}{c}\text { Actual processing } \\
\text { time (hours) }\end{array}$ & $\begin{array}{c}\text { Hours processed } \\
\text { amount }\end{array}$ & Hours Defect amount & QR \% \\
\hline 1523 & 1411 & 112 & $92,06 \%$ \\
\hline
\end{tabular}


Overall Equipment Effectiveness (OEE)

Overall Equipment Effectiveness (OEE) yaitu data efektivitas mesin yang operasi dengan waktu yang efisien untuk membuat item yang baik berdasarkan pada jadwal. OEE didapat dari availability, performance dan quality. Berdasarkan pada pengumpulan data berikut perhitungan metriknya adalah: OEE $=$ Availability $\mathrm{x}$ Performance $\mathrm{x}$ Quality.

Untuk nilai OEE selama 6 bulan tahun 2019 yaitu:

OEE $=$ Availability $\times$ Performance $\times$ Quality .....4

$=88,60 \% \times 90,55 \% \times 92,06 \%=90,40 \%$

Dengan cara ini didapat nilai OEE pada extruder line 9 selama 6 bulan tahun 2019 seperti yang ditunjukkan pada Tabel 4 berikut:

Tabel 4. Data OEE 2019

\begin{tabular}{cccc}
\hline $\begin{array}{c}\text { Actual processing time } \\
\text { (hours) }\end{array}$ & $\begin{array}{c}\text { Hours processed } \\
\text { amount }\end{array}$ & $\begin{array}{c}\text { Hours Defect } \\
\text { amount }\end{array}$ & QR \% \\
\hline 1523 & 1411 & 112 & $92,06 \%$ \\
\hline
\end{tabular}

Six big losses

Perhitungan Six Big Losses dilakukan untuk melihat pengaruh faktor efektivitas mesin berikut data persentase loss beserta dengan perhitungan time loss untuk masing-masing factor pada extruder line 9 selama 6 bulan tahun 2019 seperti yang ditunjukkan pada Tabel 5 berikut:

Tabel 5. Perhitungan six big losses

\begin{tabular}{|c|c|c|c|c|c|c|}
\hline & \multicolumn{2}{|c|}{ Availability Rate } & \multicolumn{2}{|c|}{ Performance Rate } & \multicolumn{2}{|c|}{ Quality Rate } \\
\hline & $\begin{array}{c}\text { Breakdown } \\
\text { Losses } \\
(\%)\end{array}$ & $\begin{array}{c}\text { Setup } \\
\text { And } \\
\text { Adjustm } \\
\text { ent } \\
\text { Losses } \\
(\%)\end{array}$ & $\begin{array}{c}\text { Idling } \\
\text { And } \\
\text { Minor } \\
\text { Stoppage } \\
\text { Losses } \\
(\%)\end{array}$ & $\begin{array}{c}\text { Speed } \\
\text { Losses } \\
(\%)\end{array}$ & $\begin{array}{c}\text { Quality } \\
\text { Defect } \\
\text { And } \\
\text { Required } \\
\text { Losses } \\
(\%)\end{array}$ & $\begin{array}{c}\text { Yield } \\
\text { Losses } \\
(\%)\end{array}$ \\
\hline $\begin{array}{c}\text { Total Time } \\
\text { Losses } \\
\text { (hours) }\end{array}$ & 11,40 & 0 & 0 & 9,45 & 7,94 & 0 \\
\hline $\begin{array}{c}\text { Percentage } \\
(\%)\end{array}$ & $12,87 \%$ & $0 \%$ & $0 \%$ & $10,44 \%$ & $8,62 \%$ & $0 \%$ \\
\hline
\end{tabular}

Diketahui data di atas yang memiliki time loss Availability Rate yaitu Breakdown Losses sebesar 12,87\% menyebabkan hilangnya 11,40 jam, Performance rate yaitu Speed Losses sebesar 10,44\% menyebabkan hilangnya 9,45 jam dan Quality Rate yaitu Quality Defect End Required Losses sebesar 8,62\% menyebabkan hilangnya 7,94 jam yang artinya produktivitas perusahaan perlu ditingkatkan dengan faktor time loss terbesar pada Breakdown Losses dan Speed Losses karena persentase berada diatas 10\% dari faktor Six big losses extruder line 9 selama 6 bulan tahun 2019.

\section{B. Analisa diagram sebab akibat (fishbone)}

Menemukan akar masalah akan lebih efisien dan efektif jika hanya diterapkan pada faktor six big losses yang berpengaruh terhadap besarnya produktivitas. Berikut ini diagram sebab akibat (fishbone) untuk faktor Breakdown Losses dan Speed Losses pada extruder line 9 Dapat dilihat pada Gambar 2. 


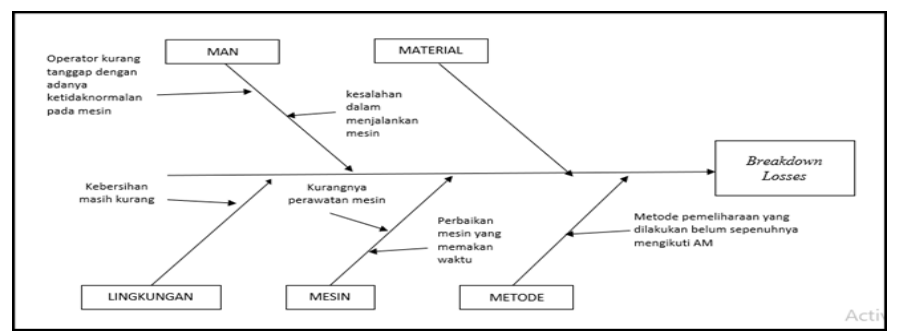

Gambar 2. Sebab akibat Breakdown Losses

Berdasarkan diagram sebab akibat (fishbone) diatas, maka didapatkan hasil analisa sebab-akibat sebagai berikut:

1. Manusia / operator

a) Operator kurang tanggap adanya ketidaknormalan pada mesin saat beroperasi karena kurang pengetahuan tentang mesin.

b) Operator kurang teliti menjalankan mesin sehingga terjadi kesalahan yang mengakibatkan adanya komponen mesin yang rusak.

2. Mesin / peralatan

a) Kurangnya perawatan dan inspeksi mesin yang mengakibatkan mesin sering rusak dan tidak beroperasi dengan optimal.

b) Proses perbaikan mesin yang memakan waktu karena spare part mesin yang susah didapat dan membutuhkan waktu yang lama dalam proses order.

3. Lingkungan

Banyak sumber kotor dan bocor di sekitar mesin yang mengganggu kinerja operator dan juga kinerja mesin.

4. Metode

Metode pemeliharaan yang dilakukan belum sepenuhnya mengikuti TPM karena hanya dilakukan oleh petugas perawatan sedangkan dari operator kurang dalam melakukan autonomous maintenance.

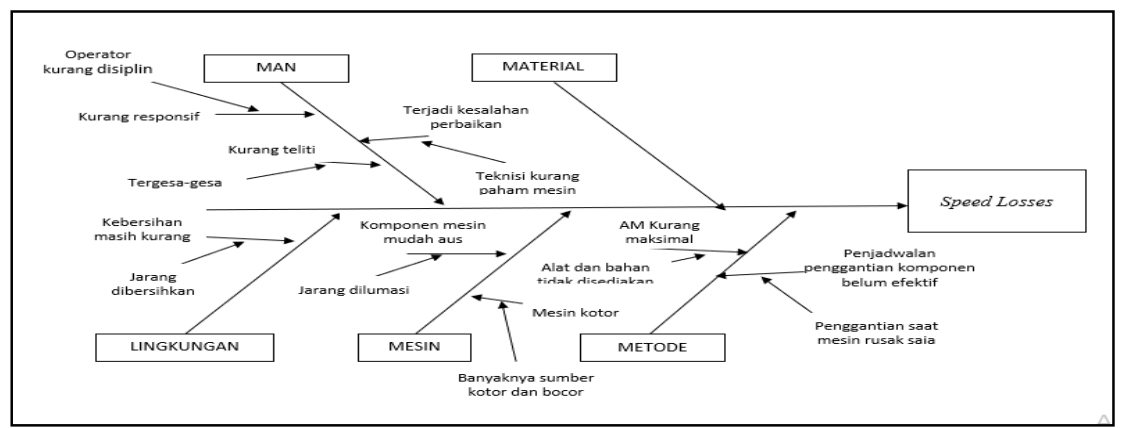

Gambar 3. Sebab akibat Speed Losses

Berdasarkan diagram sebab akibat (fishbone) diatas, maka didapatkan hasil analisa sebab-akibat sebagai berikut:

1. Manusia / operator

a) Kurang responsifnya operator dalam merawat, membersihkan dan inspeksi bagian mesin vital maka akan mengakibatkan mesin berhenti secara tiba-tiba (breakdown).

b) Kurangnya ketelitian operator dalam menjalankan serta pengawasan dalam produksi, dan ketergesaan dalam pengaturan start/stop mesin.

c) Terjadinya kesalahan dalam perbaikan mesin Extruder line 9 dikarenakan teknisi kurang memahami kerusakan pada komponen.

2. Mesin / peralatan

a) Adanya beberapa komponen-komponen dari mesin Extruder line 9 yang sangat mudah aus sehingga pada waktu tertentu akan mengakibatkan terjadinya penurunan performa pada mesin tersebut.

b) Kurangnya melakukan pembersihan pada mesin sehingga mengakibatkan banyaknya sumber kotor dan bocor yang dapat mengurangi performa pada mesin dan akan menghasilkan produk yang kurang baik, cepat aus dan terganggunya kelancaran produksi. 
3. Lingkungan

Kebersihan pada mesin kurang karena masih banyaknya sumber kotor dan bocor seperti kebocoran material, oli, dll. Sehingga dapat mengurangi efisiensi kerja operator karena keterbatasan dan kenyamanan tempat tersebut.

4. Metode

a) Autonomous maintenance kurang maksimal disebabkan karena peralatan dan bahan yang kurang mencukupi dan tidak adanya persediaan grease serta vacuum yang difungsikan untuk pembersihan pada komponenkomponen mesin.

b) Tidak efektifnya penjadwalan penggantian komponen secara berkala serta penggantian komponen mesin dilakukan ketika pada saat komponen mesin rusak saja.

\section{Usulan perbaikan masalah six big losses}

Beberapa akar permasalahan dari faktor Breakdown Losses dan Speed Losses yang dapat menurunkan produktivitas mesin Extruder line 9 antara lain permasalahan Breakdown Losses:

Table 6. Usulan Perbaikan Breakdown Losses

\begin{tabular}{|c|c|c|}
\hline Penyebab & Masalah & Usulan Perbaikan \\
\hline \multirow[t]{2}{*}{ Manusia } & $\begin{array}{l}\text { Operator kurang } \\
\text { tanggap dengan } \\
\text { adanya } \\
\text { ketidaknormalan } \\
\text { pada mesin }\end{array}$ & $\begin{array}{l}{[2]} \\
\text { Melakukan pelatihan Tagging kepada } \\
\text { operator mengenai ketidaknormalan mesin } \\
\text { dengan tujuan mengembalikan kondisi } \\
\text { mesin seperti semula } \\
\text { Lampiran hal } 53\end{array}$ \\
\hline & $\begin{array}{l}\text { Kesalahan dalam } \\
\text { menjalankan mesin }\end{array}$ & $\begin{array}{l}\text { [6] } \\
\text { 1. Memberikan pelatihan kepada operator. } \\
\text { 2. Memberikan informasi instruksi } \\
\text { kerja/OPL pada mesin tersebut } \\
\text { Lampiran hal } 54 \\
\end{array}$ \\
\hline \multirow[t]{2}{*}{ Mesin } & $\begin{array}{l}\text { Kurangnya } \\
\text { perawatan mesin }\end{array}$ & $\begin{array}{l}{[5]} \\
\text { Membuatkan standar cleaning critical yang } \\
\text { berdampak pada performance mesin. } \\
\text { Lampiran hal } 54\end{array}$ \\
\hline & $\begin{array}{l}\text { Perbaikan mesin } \\
\text { yang memakan } \\
\text { waktu }\end{array}$ & $\begin{array}{l}\text { [10] } \\
\text { Menyerahkan perbaikan dengan operator } \\
\text { yang ahli pada bidang tersebut. }\end{array}$ \\
\hline Lingkungan & $\begin{array}{l}\text { Kebersihan masih } \\
\text { kurang }\end{array}$ & $\begin{array}{l}{[10]} \\
\text { Diadakannya pengawasan secara terjadwal } \\
\text { terhadap operator saat bekerja dan adanya } \\
\text { checklist cleaning di area tersebut. } \\
\text { Lampiran hal } 55\end{array}$ \\
\hline Metode & $\begin{array}{l}\text { Metode } \\
\text { pemeliharaan yang } \\
\text { dilakukan belum } \\
\text { sepenuhnya } \\
\text { mengikuti AM. }\end{array}$ & $\begin{array}{l}{[5]} \\
\text { Memberikan pelatihan kepada operator } \\
\text { tentang kegiatan Autonomous maintenance } \\
\text { yang dilakukan setiap shift, hari, minggu } \\
\text { atau bulan oleh operator. } \\
\text { Lampiran hal } 55\end{array}$ \\
\hline
\end{tabular}

Berikut ini merupakan beberapa usulan perbaikan untuk permasalahan Speed Losses:

Table 7. Usulan Perbaikan Speed Losses

\begin{tabular}{lll}
\hline Penyebab & Masalah & \multicolumn{1}{c}{ Usulan Perbaikan } \\
\hline Manusia & Kurang & {$[5]$} \\
& responsif & 1. Melakukan pengecekan kesiapan mesin dengan \\
& checklist persiapan start dengan teliti pada saat \\
& sebelum start up. \\
& Lampiran hal 56 \\
& 2. Melakukan serah terima sebelum pergantian \\
& shift dengan memberikan informasi kendala- \\
& kendala selama shift tersebut. \\
\hline
\end{tabular}




\begin{tabular}{|c|c|c|}
\hline & & $\begin{array}{l}\text { 3. Melakukan pelatihan rutin kepada operator } \\
\text { mengenai troubelshooting. } \\
\text { 4. Mengevaluasi implementasi TPM untuk } \\
\text { mengukur efektivitas yang didapat. }\end{array}$ \\
\hline & Kurang teliti & $\begin{array}{l}\text { [6] } \\
\text { 1. Melakukan penilaian kepada setiap operator } \\
\text { 2. Memberikan pelatihan kepada operator }\end{array}$ \\
\hline & $\begin{array}{l}\text { Terjadinya } \\
\text { kesalahan } \\
\text { dalam } \\
\text { perbaikan } \\
\text { mesin }\end{array}$ & $\begin{array}{l}{[10]} \\
\text { Memberikan pelatihan kepada maintenance agar } \\
\text { lebih ahli untuk mengerjakan perbaikan ataupun } \\
\text { perawatan berkala pada mesin }\end{array}$ \\
\hline \multirow[t]{2}{*}{ Mesin } & $\begin{array}{l}\text { Komponen } \\
\text { mesin } \\
\text { mudah aus }\end{array}$ & $\begin{array}{l}{[5]} \\
\text { Membuatkan standar cleaning dan lubrikasi yang } \\
\text { efektif sehingga dapat mengurangi waktu untuk } \\
\text { pengerjaannya } \\
\text { Lampiran hal } 56\end{array}$ \\
\hline & Mesin Kotor & $\begin{array}{l}{[5]} \\
\text { Melakukan cleaning secara berkala di sekitar area } \\
\text { kerja dan melakukan perbaikan untuk } \\
\text { menghilangkan atau meminimalisir area sumber } \\
\text { kotor dan sumber bocor. }\end{array}$ \\
\hline Lingkungan & $\begin{array}{l}\text { Kebersihan } \\
\text { pada mesin } \\
\text { kurang }\end{array}$ & $\begin{array}{l}\text { [10] } \\
\text { 1. Membersihkan mesin bagian luar dan dalam } \\
\text { 2. Menghilangkan atau meminimalisir area sumber } \\
\text { kotor dan sumber bocor. } \\
\text { Lampiran hal } 57\end{array}$ \\
\hline \multirow[t]{2}{*}{ Metode } & $\begin{array}{l}\text { Autonomous } \\
\text { maintenance } \\
\text { kurang } \\
\text { maksimal }\end{array}$ & $\begin{array}{l}\text { [2] } \\
\text { 1. Reset based level yaitu memaksimalkan } \\
\text { kegiatan AM harian oleh operator pada aktivitas } \\
\text { pembersihan, inspeksi mesin dan pelumasan } \\
\text { mesin. } \\
\text { Lampiran hal } 58 \\
\text { 2. Menerapkan autonomous maintenance di setiap } \\
\text { working station. } \\
\text { 3. Menyiapkan alat dan bahan, seperti grease }\end{array}$ \\
\hline & $\begin{array}{l}\text { Penjadwalan } \\
\text { penggantian } \\
\text { komponen } \\
\text { belum } \\
\text { efektif }\end{array}$ & $\begin{array}{l}\text { [6] } \\
\text { 1. Melakukan evaluasi dan menyesuaikan terhadap } \\
\text { kondisi di lapangan supaya SOP dapat berjalan } \\
\text { dengan baik. } \\
\text { 2. Pelaksanaan pemeliharaan mesin mengacu pada } \\
\text { jadwal PM rutin. }\end{array}$ \\
\hline
\end{tabular}

\section{Implementasi usulan perbaikan}

Berikut hasil setelah dilakukannya usulan perbaikan Breakdown Losses dan Speed Losses di extruder line 9 berupa data OEE sebagai berikut;

Tabel 8. Data OEE 2020

\begin{tabular}{cccc}
\hline Availability Rate $\%$ & Performance Rate $\%$ & Quality Rate\% & OEE\% \\
\hline 92,21 & 93,96 & 94,78 & 93,65 \\
\hline
\end{tabular}

Dari data di atas setelah dilakukan usulan perbaikan di extruder line 9 selama 6 bulan tahun 2020 data OEE mengalami peningkatan sebesar 3,25\% serta Availability rate naik sebesar 3,61\%, Performance rate naik sebesar $3,41 \%$ dan Quality rate naik sebesar 2,72\%.Beberapa usulan perbaikan antara lain tagging, memberikan informasi instruksi kerja, standar checklist cleaning critical dan lainnya pada usulan perbaikan Tabel 6 dan Tabel 7.

\section{KESIMPULAN}

Merencanakan usulan perbaikan Breakdown Losses dan Speed Losses di extruder line 9 yang dilakukan untuk meningkatkan nilai Availability rate, Performance rate dan OEE dengan usulan perbaikan masalah six big losses 
seperti pada Tabel 6 dan Tabel 7 didapatkan nilai Availability rate mengalami peningkatan sebesar 3,61\%, Performance rate mengalami peningkatan sebesar 3,41\% dan OEE mengalami peningkatan sebesar 3,25\% setelah dilakukan usulan perbaikan di extruder line 9 selama 6 bulan tahun 2020 .

Dengan meningkatkan pengetahuan, ketrampilan, dan tanggung jawab operator produksi terkait ketidaknormalan pada mesin dapat diminimalisir antara lain melalui proses tagging, mendaftar area yang sulit dicleaning, inspeksi, lubrikasi dan tightening (CILT) adanya standar checklist critical pada mesin dan checklist lubrikasi serta usulan perbaikan yang terdapat pada Tabel 6 dan Tabel 7 sehingga dapat membantu perawatan mesin hingga berhasil mengembalikan peralatan kembali ke kondisi dasarnya.

\section{REFERENSI}

[1] A. Achyari, Materi Pokok Manajemen Operasi, 2nd ed. Tangerang Selatan: Universitas Terbuka, 2017.

[2] M. B. Anthony, “Analisis Penerapan Total Productive Maintenance (TPM) Menggunakan Overall Equipment Efectiveness (OEE) Dan Six Big Losses Pada Mesin Cold Leveller PT. KPS,” JATI UNIK : Jurnal Ilmiah Teknik dan Manajemen Industri, vol. 2, no. 2, pp. 94-103, Apr. 2019, doi: 10.30737/jatiunik.v2i2.333.

[3] J. A. Brydson, Plastics Materials, 7th ed. United Kingdom: Butterworths-Heinemann, 1999.

[4] N. Hairiyah, R. Rizki, and R. A. Wijaya, "ANALISIS TOTAL PRODUCTIVE MAINTENANCE (TPM) PADA STASIUN KERNEL CRUSHING PLANT (KCP) DI PT. X,” Jurnal Teknologi Pertanian Andalas, vol. 23, no. 1, pp. 103-110, Mar. 2019, doi: 10.25077/jtpa.23.1.103-110.2019.

[5] A. A. Hamza, "Analisa Total Productive Maintenance Dengan Menggunakan Metode Overall Equipment Effectiveness Di PT Karung Emas," Matrik: Jurnal Manajemen dan Teknik Industri Produksi, vol. 16, no. 1, pp. 33-50, Sep. 2018, doi: 10.30587/matrik.v16i1.550.

[6] J. M. Tupan, A. Simanjuntak, and L. Aditiar, "Evaluasi Efektivitas Pemeliharaan Menggunakan Alat Reminder Pemeliharaan dengan Penerapan Total Productive Maintenance di PT. PLN (Persero) Rayon Haruku," ARIKA, vol. 12, no. 1, pp. 25-40, Mar. 2018, doi: 10.30598/arika.2018.12.1.25.

[7] E. Krisnaningsih, "USULAN PENERAPAN TPM DALAM RANGKA PENINGKATAN EFEKTIFITAS MESIN DENGAN OEE SEBAGAI ALAT UKUR DI PT XYZ," PROSISKO: Jurnal Pengembangan Riset dan Observasi Sistem Komputer, vol. 2, no. 2, Sep. 2015.

[8] S. Nakajima, Introduction to TPM: Total Productive Maintenance. New York: Productivity Press, 1988.

[9] N. H. Sari, Material Teknik. Yogyakarta : Deepublish, 2018.

[10] N. C. Dewi and D. I. Rinawati, “ANALISIS PENERAPAN TOTAL PRODUCTIVE MAINTENANCE (TPM) DENGAN PERHITUNGAN OVERALL EQUIPMENT EFECTIVENESS (OEE) DAN SIX BIG LOSSES MESIN CAVITEC PT. ESSENTRA SURABAYA (STUDI KASUS PT. ESSENTRA)," Industrial Engineering Online Journal, vol. 4, no. 4, 2015.

[11] M. P. Stephens, Productivity and Reliability-Based Maintenance Management. United States: Purdue University Press, 2010.

[12] M. Tajiri and F. Gotō, TPM Implementation, a Japanese Approach. United States: McGraw-Hill, 1992.

[13] M. W. Wakjira and A. S. Iyengar, "Autonomous Maintenance: A Case Study on Assela Malt Factory," Bonfring International Journal of Industrial Engineering and Management Science, vol. 4, no. 4, pp. 170-178, Nov. 2014, doi: 10.9756/BIJIEMS.10364. 